
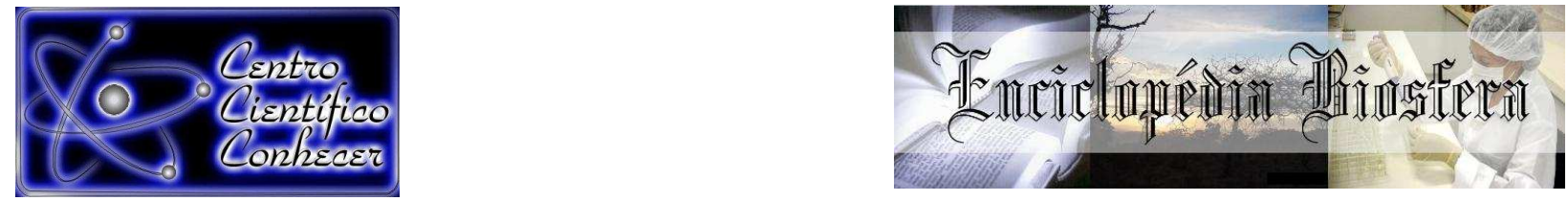

\title{
PERSPECTIVAS RELACIONADAS AO ESTUDO DA BIOLOGIA SOB O OLHAR DOS ALUNOS DO ENSINO MÉDIO
}

Marlon Henrique Borges de Resende ${ }^{* 1}$, Luciana Aparecida Siqueira Silva ${ }^{2}$, Lucas Donizetti Vieira $^{1}$, Daniele Cipriano de Souza ${ }^{1}$, Christina Vargas Miranda e Carvalho ${ }^{3}$

${ }^{1}$ Licenciando em Ciências Biológicas do Instituto Federal Goiano - Campus Urutaí. Urutaí, GO, Brasil ("${ }^{*}$ e-mail: marlonhborges@gmail.com)

${ }^{2}$ Professora do Núcleo de Ciências Biológicas do Instituto Federal Goiano - Campus Urutaí. Urutaí, GO, Brasil

${ }^{3}$ Professora do Núcleo de Química do Instituto Federal Goiano - Campus Urutaí. Urutaí,GO, Brasil

Recebido em: 08/09/2015 - Aprovado em: 14/11/2015 - Publicado em: 01/12/2015 DOI: http://dx.doi.org/10.18677/Enciclopedia_Biosfera_2015_054

\begin{abstract}
RESUMO
Este trabalho teve por objetivo saber como os alunos definem a Biologia e aspectos que demonstram como a disciplina de biologia tem sido trabalhada nas escolas públicas e privadas. O trabalho foi realizado durante os meses de maio e junho de 2014, e contou com a participação voluntária de alunos matriculados na $3^{\text {a }}$ série do Ensino Médio regular em duas escolas públicas e quatro particulares. A obtenção e análise dos dados foram realizadas a partir da escala de Likert modificada, observando intervalos específicos das notas atribuídas pelos discentes. Foram investigados 120 alunos voluntários pertencentes a 12 turmas, com faixa etária de 17 a 21 anos. Os alunos concordaram ou concordaram plenamente com as definições de biologia a eles apresentadas, foram essas, conceitual, científica, ecológica, zoológica e antropológica. Foi apontado nos dois modelos de instituições que a falta de laboratórios e de aulas práticas interfere negativamente no ensino de biologia. Os principais pontos negativos dos professores de biologia foram a tolerância à indisciplina nas escolas públicas e a exigência de resumos de capítulos nas escolas particulares. Para os discentes a principal aplicação da biologia é a formação para o ENEM/vestibular. Os alunos que alegaram ter recebido influência da Biologia na escolha da profissão almejam em sua maioria cursar Ciências Biológicas ou Medicina Veterinária. Para os alunos tanto de escolas públicas como particulares a definição de Biologia é que se trata de uma disciplina conceitual, caracterizada pelo estudo dos seres vivos e do ser humano.
\end{abstract}

PALAVRAS-CHAVE: ensino de biologia; indisciplina escolar; metodologia de ensino.

\section{PERPECTIVES RELATED TO THE STUDY OF BIOLOGY UNDER THE LOOK OF HIGH SCHOOL STUDENTS}

\footnotetext{
ABSTRACT

This study aimed to find out how students define the biology, and aspects that demonstrate how the discipline of biology has been worked in public and private
} 
schools. The study was conducted during the months of May and June 2014 and included the voluntary participation of students enrolled in the 3rd series of the regular high school in two public and four private schools. The collection and analysis of data were made from the modified Likert scale, noting specific ranges of grades given by students. 120 students volunteers were investigated belonging to 12 classes, aged 17-21 years. The students agreed or strongly agreed with the biology settings presented to them, were these, conceptual, scientific, ecological, zoological and anthropological. It was appointed in two models of institutions that lack of laboratories and practical classes negatively interfere in biology teaching. The main negatives biology teachers were tolerance to indiscipline in public schools and the requirement of chapters summaries in private schools. For the students the main application of biology is training for ENEM / entrance exam. Students who claimed to have been influenced by biology in the profession choice crave mostly attend Biological Sciences and Veterinary. For students of both public and private schools, Biology definition is that it is a conceptual discipline, characterized by the study of living things and human.

KEYWORDS: biology teaching; indiscipline school; teaching methodology.

\section{INTRODUÇÃO}

Parte do processo de ampliação e construção de conhecimentos é feita durante o período em que o aluno vivencia o ambiente escolar, o qual tem importante papel no desenvolvimento de um indivíduo que perceba, pense e saiba atuar no meio em que vive. O ensino da Biologia desempenha papel importante junto às demais disciplinas, considerando que existe um contexto mundial regido pelo desenvolvimento científico e tecnológico. PINHEIRO et al. (2009) afirmam que o desenvolvimento da ciência e da tecnologia tem acarretado diversas transformações na sociedade contemporânea. Segundo DELORS (2005), a educação é considerada como o principal fator que pode proporcionar prosperidade econômica e também, atuar como combustível durante o progresso científico e tecnológico.

Com a Biologia se destacando em meio às ciências de ponta, é possível perceber a indubitável relevância da mesma no cotidiano dos cidadãos, e quem tem o papel principal de levar esse conhecimento a todos é a escola. Essa escola, segundo as concepções de GIORDAN \& VECCHI (1996), não pode se limitar ao ensino de conhecimentos enciclopédicos, que são temporariamente armazenados pelos alunos, mas sim, em um primeiro momento, organizar e gerenciar um fluxo de conhecimentos de forma que estes possam ser mobilizados na resolução de problemas e entendimento de situações que fazem parte da atual realidade.

As peculiaridades dos discentes, perceptíveis no contexto escolar, vão de encontro a Teoria das Inteligências Múltiplas (Linguística, Musical, Espacial, LógicoMatemática, Corporal, Pessoal e Naturalista) proposta por GARDNER (1994). Esta teoria afirma que cada indivíduo tem uma habilidade específica, fazendo com que o mesmo assimile e expresse o saber de formas diferentes; tais peculiaridades corroboram no desenvolvimento de atividades que sejam adequadas aos mesmos, e ainda, para um ambiente educacional mais amplo e variado, que dependa menos do desenvolvimento único e exclusivo da linguagem e da lógica. Seguindo nesta linha de raciocínio, KRASILCHIK (2011) no que diz respeito as ideias básicas de Vygotsky, afirma que cada aluno aprende de uma forma diferente e, portanto, o uso de métodos uniformes não é tão eficiente e abrangente na relação ensinoaprendizagem. 
Os métodos utilizados no ensino de Biologia, assim como em outras ciências são sempre colocados em xeque, tendo em mente a importância no processo ensino-aprendizagem. Muitas iniciativas são encontradas, mas pouco se vê na realidade das escolas. O mau uso de variados métodos de ensino e/ou utilização de apenas um, somado a deficiência na formação dos professores nos cursos de licenciatura e diversos outros aspectos, são discussões importantes acerca de problemas cada vez mais complexos, que não se prestam a soluções mágicas e simplificadoras (SCHWARTZMAN \& BROCK, 2005). Um aprendizado de sucesso, segundo DEMO (2009), está atrelado à responsabilidade social e pedagógica, mas também a um compromisso humanista.

Vê-se no meio escolar grande dificuldade por parte dos alunos em manter o foco nos objetivos da sala de aula e, uma das principais causas, pode ser a introdução crescente de aparatos tecnológicos no contexto escolar. Assim, esses alunos não se encontram receptivos ao aprendizado e, de acordo com MORAN (2007), para que o aluno consiga aprender precisa estar receptivo à informação, por meio da identificação dos empecilhos na recepção dessa informação é que pode gerar uma mudança positiva que vá resultar em uma efetiva relação ensinoaprendizagem.

O ensino de Biologia ainda tem se mostrado, de acordo com BORGES \& LIMA (2007), um ensino organizado de forma a privilegiar o estudo de conceitos, metodologias e linguagem desse campo do conhecimento, tornando o aprender em sala de aula pouco eficiente para interpretação e intervenção na realidade. Com a realização deste trabalho, objetivou-se saber como os alunos definem a Biologia e os aspectos que demonstram como a disciplina de Biologia tem sido trabalhada nas escolas públicas e privadas da cidade de Pires do Rio, Goiás.

\section{MATERIAL E MÉTODOS}

O trabalho foi realizado durante os meses de maio e junho de 2014, contando com a participação voluntária de alunos matriculados na $3^{\underline{a}}$ série do Ensino Médio regular em quatro instituições privadas e duas públicas, localizadas na cidade de Pires do Rio - GO. A amostra foi composta por 10 alunos voluntários de cada turma, totalizando120 alunos pertencentes a 12 turmas, com faixa etária de 17 a 21 anos. Para que fosse realizada a coleta de dados optou-se pela aplicação de um questionário investigativo (ANEXO I), tendo os participantes maiores de 18 anos assinado um Termo de Consentimento Livre e Esclarecido (TCLE). Com relação aos participantes menores de idade, o TCLE foi assinado por seus respectivos responsáveis.

$\mathrm{Na}$ primeira seção, o instrumento investigativo é composto por variáveis que buscam suscitar o perfil dos discentes e as partes subsequentes foram formadas por questões que se encontram relacionadas aos diversos aspectos que circundam a Biologia em sala de aula. Ainda sobre as partes subsequentes do questionário, na segunda seção tem-se a divisão de oito itens a serem avaliados pelos respondentes: definição de Biologia; fatores negativos no ensino; componentes de uma boa aula; pontos negativos em um professor da disciplina abordada neste trabalho; utilidade da mesma no Ensino Médio; a relação que os alunos possuem com a disciplina; o que os discentes esperam do professor perante a indisciplina e métodos de ensino utilizados pelo professor em sala de aula. Ao final do questionário, na terceira seção, há uma questão provocativa que os possibilitou refletir sobre a influência da Biologia durante o período em que cursou o Ensino Médio na escolha da futura profissão. 
Na primeira e terceira seções, a análise do conteúdo foi realizada por meio do método de contagem por incidência das respostas observadas, apresentando-se o número de vezes em que a mesma resposta foi observada. Os dados pertencentes à segunda seção foram coletados por meio de uma escala Likert modificada (LIKERT, 1932). Para a realização da análise dos dados sobre as variáveis obtidas levou-se em consideração a média das notas atribuídas pelos discentes e os intervalos apresentados na Tabela 1.

TABELA 1. Relação do intervalo de médias das notas atribuídas e variáveis consideradas

\begin{tabular}{cc}
\hline Variáveis consideradas & Intervalo de média das notas atribuídas \\
\hline Concordo plenamente & 1,0 a 1,75 \\
Concordo & 1,76 a 2,51 \\
Discordo & 2,52 a 3,27 \\
Discordo plenamente & 3,28 a 4,0 \\
\hline
\end{tabular}

É válido salientar que, o questionário investigativo utilizado passou por um processo de validação, antes que ocorresse a sua real aplicação em sala de aula. Este processo de validação é ressaltado por LIMA (2000), quando o mesmo aponta os passos para a construção da escala. MATTAR (2001) explana que os números atribuídos singularmente a cada resposta são o reflexo da atitude de cada respondente no que diz respeito a cada afirmação.

\section{RESULTADOS E DISCUSSÃO}

A partir dos dados coletados na seção 1 do questionário, obteve-se a mesma porcentagem de discentes do sexo feminino $(55 \%)$ e masculino $(45 \%)$ em ambas classificações das instituições escolares. Foi observado que o maior percentual $(13,33 \%)$ de reprovações, dependência ou repetição do ano escolar tem a disciplina de Biologia como uma das matérias que acarretou esse fato, isso dentro das escolas privadas. Em contraste com as instituições de ensino básico privadas, nas escolas públicas, foi identificado $3 \%$ de reprovação na matéria.

Os dados coletados na seção 2 do questionário serão apresentados a seguir, com base nas variáveis consideradas na Tabela 1. Quanto à investigação acerca dos conceitos de Biologia que são expressos pelos alunos, foram expostas cinco afirmativas por meio de questionário (Tabela 2), com o intuito de resgatar os conhecimentos assimilados durante as séries anteriores e entender o que os alunos denominam como Biologia, com definições fundamentadas em estudo realizado por MALAFAIA et al. (2010).

TABELA 2. Definições atribuídas à Biologia segundo os alunos respondentes

\begin{tabular}{ccc}
\hline \multirow{2}{*}{ Definições } & \multicolumn{2}{c}{ Média das notas } \\
\cline { 2 - 3 } & Escolas públicas & Escolas privadas \\
\hline Conceitual & 1,60 & 1,51 \\
Científica & 1,82 & 1,93 \\
Ecológica & 1,70 & 1,62 \\
Zoológica & 1,99 & 1,66 \\
Antropológica & 1,67 & 1,58 \\
\hline
\end{tabular}


A partir da Tabela 1, percebe-se que tantos os alunos das escolas públicas quanto de escolas privadas concordam e/ou concordam plenamente com as referidas definições atribuídas à Biologia. É necessário ressaltar que, as definições que são construídas pelos alunos ao longo do período escolar, são fundamentadas, principalmente, no que é apresentado pelos professores em sala de aula e, portanto, é necessário que os docentes trabalhem o significado da Biologia de forma clara e abrangente. MALAFAIA et al. (2010) ressaltam que, ao expor abrangência e complexidade da Biologia ou Ciências Biológicas, o docente traz a disciplina ao encontro do cotidiano do aluno, despertando maior interesse do discente pela mesma.

$\mathrm{Na}$ busca por entender como o ensino de Biologia tem sido realizado e os aspectos que o envolvem, foram ainda investigadas outras questões do ponto de vista dos discentes. Os estudantes puderam definir o seu grau de concordância com afirmativas relacionadas a alguns fatores que interferem negativamente no ensino de Biologia nas escolas (Tabela 3).

TABELA 3. Fatores que interferem negativamente no ensino de Biologia na percepção dos alunos respondentes

\begin{tabular}{|c|c|c|}
\hline \multirow{2}{*}{ Fatores considerados } & \multicolumn{2}{|c|}{ Média das notas } \\
\hline & Escolas públicas & Escolas privadas \\
\hline A grande quantidade de termos técnicos & 2,25 & 2,27 \\
\hline $\begin{array}{l}\text { Grande volume de informação em um curto } \\
\text { espaço de tempo }\end{array}$ & 1,75 & 2,36 \\
\hline Indisciplina e desinteresse dos alunos & 1,95 & 1,91 \\
\hline $\begin{array}{l}\text { Falta de qualificação adequada dos } \\
\text { professores }\end{array}$ & 1,94 & 2,41 \\
\hline Falta de laboratórios e aulas práticas & 1,50 & 1,53 \\
\hline
\end{tabular}

Os alunos concordaram que "o excesso de vocabulário técnico interfere de forma negativa nas aulas de Biologia" (Tabela 3). KRASILCHIK (2011) afirma que esse excesso tem como consequência fazer com que os alunos vejam a referida disciplina como um conjunto de nomes a serem memorizados. A referida autora colabora ainda dizendo que, os termos utilizados só terão sentido para o aluno quando the ocorrem situações em que ele os possa usar, possibilitando que o mesmo construa suas próprias associações, e consequentemente, um melhor entendimento do que the é exposto em sala de aula. HOFFMANN \& SCHEID (2007) apontam que analogias bem construídas, compostas por elementos do cotidiano do próprio aluno, utilizadas na tentativa de realizar uma aproximação do aluno e o conhecimento científico, são elementos facilitadores da aprendizagem.

Foram apresentados aos alunos aspectos considerados negativos em um professor de Biologia. Na Tabela 4, encontram-se as notas médias que os alunos atribuíram aos mesmos. 
TABELA 4. Aspectos negativos de um professor de Biologia na opinião dos alunos respondentes

\begin{tabular}{ccc}
\hline Aspectos considerados & \multicolumn{2}{c}{ Média das notas } \\
\cline { 2 - 3 } & Escolas públicas & Escolas privadas \\
\hline $\begin{array}{c}\text { Leitura de textos e memorização de } \\
\text { conceitos }\end{array}$ & 1,92 & 1,97 \\
Exigência de resumos de capítulos & 2,08 & 2,13 \\
$\begin{array}{c}\text { Insegurança relacionada à falta de } \\
\text { domínio do conteúdo }\end{array}$ & 1,58 & 1,57 \\
$\quad \begin{array}{c}\text { Tolerância à indisciplina } \\
\text { Relação desarmônica com a turma }\end{array}$ & 2,37 & 1,47 \\
\end{tabular}

Os alunos respondentes concordam com praticamente todos os aspectos considerados negativos em um professor de Biologia. No entanto, ao ser considerada a "insegurança relacionada à falta de domínio de conteúdo", alunos de escolas públicas e privadas concordam plenamente com este aspecto e, no que se refere à "tolerância à indisciplina", a percepção dos discentes é concebida de forma diferente nas escolas públicas e privadas. Enquanto os alunos das instituições públicas apenas concordam, alunos das instituições privadas possuem total concordância com a afirmação.

Tem-se na primeira afirmativa, que os alunos concordam que a leitura de textos e memorização de conceitos não são características bem aceitas no meio. Ainda assim, MALAFAIA \& RODRIGUES (2008) discutem que, a memorização de saberes biológicos é uma prática que proporciona uma melhoria significante no ensino básico, auxiliando no processo de compreensão das informações.

Com as constantes transformações de conceitos e formação de ideologias que ocorrem nesse período, faz-se necessário compreender o que os discentes têm entendido como aplicações da Biologia nas séries do Ensino Médio. Pensando nisso, foi investigada a opinião dos alunos acerca das referidas aplicações da Biologia (Tabela 5).

TABELA 5. Aplicações da Biologia no Ensino Médio de acordo com a opinião dos alunos respondentes

\begin{tabular}{|c|c|c|}
\hline \multirow{2}{*}{$\begin{array}{l}\text { recursos naturais } \\
\text { Aplicações } \\
\text { Entender melhor as relações do ser } \\
\text { humano com o ambiente }\end{array}$} & \multicolumn{2}{|c|}{1,70 Média das notas } \\
\hline & Escolas, \$óblicas & Escolas, privadas \\
\hline Formação para ENEN|/vestibutar & 1,53 & 1,40 \\
\hline $\begin{array}{l}\text { Aquisição de informações úteis ao } \\
\text { cotidiano }\end{array}$ & 1,90 & 1,68 \\
\hline $\begin{array}{c}\text { Compreender sobre prevenção de } \\
\text { doenças }\end{array}$ & 1,82 & 1,58 \\
\hline
\end{tabular}


É possível destacar que, nas escolas públicas e privadas os alunos concordaram plenamente que "a disciplina de Biologia tem como função auxiliar em processos para o ingresso no Ensino Superior" (Exame Nacional do Ensino Médio ENEM e vestibulares), o que é um problema se for considerada apenas esta afirmação, já que este não é o objetivo central da disciplina que, conforme orientações contidas nos Parâmetros Curriculares Nacionais do Ensino Médio (BRASIL, 2002) deve contribuir para a formação integral do cidadão, ao afirmar que

Num mundo como o atual, de tão rápidas transformações e de tão difíceis contradições, estar formado para a vida significa mais do que reproduzir dados, denominar classificações ou identificar símbolos. Significa:

- saber se informar, comunicar-se, argumentar, compreender e agir;

- enfrentar problemas de diferentes naturezas;

- participar socialmente, de forma prática e solidária;

- ser capaz de elaborar críticas ou propostas; e,

- especialmente, adquirir uma atitude de permanente aprendizado. (p. 9)

Para os alunos que se encontram em sequência de escolarização regular, na faixa etária de 15 a 17 anos, o Ensino Médio tem como representação mais do que apenas uma última etapa da Educação Básica. De acordo com VIGOTSKI (1996) nessa idade 0 indivíduo finda a sua capacidade de pensar por conceitos, transformando o conteúdo do seu pensamento. Passa a existir uma necessidade de ampliação dos conhecimentos, gerando novos modos de pensar. Com as constantes transformações de conceitos e formação de ideologias que ocorrem nesse período, faz-se necessário compreender o que os discentes têm entendido por aplicações da biologia nas séries do ensino médio.

Os alunos das instituições privadas concordam plenamente que "a Biologia atua como fonte de informações úteis à vida cotidiana" e "na prevenção de doenças", já nas instituições públicas os discentes apenas concordaram com a respectiva afirmação. Observa-se nesse contexto a importância da disciplina como um instrumento de saúde pública, atuando na conscientização dos estudantes acerca de inúmeras doenças. Essa abordagem durante o Ensino Básico, de acordo com SANMARTí (1998) é importante, pois atinge-se indivíduos em fase de formação mental e social, que se encontram abertos a aprender novos hábitos e assimilar conhecimento.

Os alunos das escolas públicas e privadas concordam plenamente que "a Biologia contribui para maior conservação dos recursos naturais" e, ainda, "possibilita entender melhor as relações do ser humano com o ambiente". Assim, a disciplina de Biologia proporciona uma formação biológica, que segundo KRASILCHIK (2011, p. 13), "contribui para que cada cidadão se torne apto a compreender e aprofundar as explicações atualizadas de processos e de conceitos biológicos, a importância da ciência e da tecnologia na sociedade moderna". E ainda, segundo a mesma autora, contribuem para a tomada de decisões de interesse individual e coletivo, dentro de um quadro ético de responsabilidade e respeito que leve em conta o papel do homem na biosfera.

Tão importante quanto compreender os questionamentos abordados anteriormente, é conhecer a relação entre o estudante e a disciplina de Biologia, apresentado na Tabela 6. 
TABELA 6. Relação dos discentes respondentes com a disciplina Biologia

\begin{tabular}{|c|c|c|}
\hline \multirow{2}{*}{ Aspecto considerado } & \multicolumn{2}{|c|}{ Média das notas } \\
\hline & Escolas públicas & Escolas privadas \\
\hline $\begin{array}{c}\text { Possui interesse pelos assuntos e participativo } \\
\text { durante as aulas }\end{array}$ & 1,81 & 1,70 \\
\hline $\begin{array}{l}\text { Busca informações além do conteúdo de sala de } \\
\text { aula }\end{array}$ & 2,43 & 2,37 \\
\hline $\begin{array}{c}\text { Acha que os conhecimentos da disciplina facilitam } \\
\text { a compreensão de fatos cotidianos }\end{array}$ & 1,95 & 1,56 \\
\hline Acha os conteúdos extremamente complexos & 1,99 & 2,53 \\
\hline $\begin{array}{l}\text { Possui respeito pelos seres vivos e se preocupa } \\
\text { com a conservação da biodiversidade }\end{array}$ & 1,64 & 1,73 \\
\hline
\end{tabular}

Os discentes das escolas públicas e privadas concordaram ou concordaram plenamente em quase todas as afirmativas inerentes à "sua relação com a Biologia", apontando seu interesse pelos assuntos abordados nas aulas e, ainda, consideram que os conhecimentos da disciplina facilitam a compreensão de fatos cotidianos. Há ressalva para a afirmação relacionada à "complexidade dos conteúdos abordados na disciplina", na qual os alunos das escolas públicas concordam e os das escolas privadas discordam. SCHELEY et al. (2014) apontam que:

\begin{abstract}
"faz-se necessário que os professores revejam a relação entre motivação intrínseca e extrínseca e seu papel no processo motivacional dos alunos. A curiosidade do aluno precisa ser mobilizada e a relevância do conteúdo compreendida, por meio de interações e de atividades que solicitem a participação dos alunos e Ihes possibilitem desenvolver a auto-estima" ( $p$. 4973).
\end{abstract}

Observando as tabelas anteriores, é possível verificar que a palavra "indisciplina" se encontra presente em algumas afirmações julgadas e é fato que a indisciplina existe como um problema recorrente na maioria das salas de aula, afetando o processo ensino-aprendizagem. Indagações acerca da indisciplina não são algo recente perante o campo da educação, e na literatura educacional há registros seculares do embate entre os professores e essas expressões (GILES, 1987). Observando a importância desse aspecto para o contexto da sala de aula, resolveu-se questionar os alunos sobre quais atitudes o professor deveria tomar diante da ocorrência da indisciplina em sala (Tabela 7).

TABELA 7. Atitudes do professor perante a indisciplina na percepção dos alunos respondentes

\begin{tabular}{|c|c|c|}
\hline \multirow{2}{*}{ Atitudes } & \multicolumn{2}{|c|}{ Média das notas } \\
\hline & Escolas públicas & Escolas privadas \\
\hline $\begin{array}{c}\text { Punir o aluno expulsando-o da sala ou } \\
\text { advertindo-o verbalmente }\end{array}$ & 2,32 & 1,93 \\
\hline $\begin{array}{l}\text { Conversar com o aluno, procurando entender } \\
\text { os motivos que o levam ao desinteresse }\end{array}$ & 1,45 & 1,87 \\
\hline $\begin{array}{c}\text { Planejar e realizar atividades práticas e } \\
\text { interativas }\end{array}$ & 1,25 & 1,51 \\
\hline $\begin{array}{l}\text { Associar os conteúdos a assuntos } \\
\text { considerados interessantes pelos alunos }\end{array}$ & 1,36 & 1,40 \\
\hline Desprezar o aluno desinteressado & 3,23 & 3,15 \\
\hline
\end{tabular}


Os discentes de escolas públicas e privadas concordaram que expulsar o aluno de sala de aula ou adverti-lo verbalmente são atitudes que o professor deve ter perante a indisciplina. Os alunos da escola privada concordaram ainda que 0 professor deve estabelecer uma relação de diálogo com o aluno indisciplinado, na tentativa de entender os motivos que o levaram a esse comportamento. Já na escola pública os alunos concordaram plenamente com a referida atitude. No entanto, tanto alunos de escolas públicas quanto de escolas privadas, discordam que o professor deve desprezar o aluno desinteressado. Nessa perspectiva, BELOTTI \& FARIA (2010) afirmam que todo educador apresenta-se como uma referência para a formação dos educandos e, é muito importante a maneira como se relaciona com eles.

AQUINO (1998) aponta três possíveis causas básicas da indisciplina: (i) o atual aluno é menos respeitador que os alunos de antes e a escola se tornou mais permissiva; (ii) as crianças de hoje em dia não reconhecem autoridade, não se submetem a regras, sendo assim a responsabilidade é da família; e (iii) que talvez a sala de aula não seja tão atrativa quanto os outros meios de comunicação, caindo a culpa sobre o professor que não inova e prende a atenção do seu aluno.

Os estudantes respondentes foram questionados ainda quanto às metodologias utilizadas por seus professores no ensino de Biologia, estando o resultado exposto na Tabela 8.

TABELA 8. Métodos utilizados pelos professores de Biologia de acordo com os alunos respondentes

\begin{tabular}{ccc}
\hline Metodologia de ensino & \multicolumn{2}{c}{ Média das notas } \\
\cline { 2 - 3 } & Escolas públicas & Escolas privadas \\
\hline Aulas práticas em sala e/ou laboratório & 2,41 & 2,65 \\
Aula expositivo-dialogada utilizando & 1,67 & 1,67 \\
livro didático, quadro e giz & 2,38 & 2,25 \\
Vídeo aulas & 2,76 & 2,82 \\
Excursões & 1,95 & 1,96 \\
Debates ou discussões & & \\
\hline
\end{tabular}

Os discentes concordaram plenamente que as aulas expositivo-dialogadas utilizando livro didático, quadro e giz são utilizadas na escola privada e pública. Foi observado que em escolas privadas o hábito de usar aulas práticas para dinamizar o ensino de Biologia não são utilizadas, visto que os alunos discordam plenamente dessa afirmação. Segundo VIEIRA et al. (2015), ao deixar de utilizar atividades práticas no ensino de Biologia, priva-se os alunos de uma visão mais ampla relacionada às estruturas e fenômenos biológicos, fazendo com que as aulas se tornem previsíveis e monótonas. SOUTO et al. (2015) destacam que por meio da experimentação é possível promover nos alunos o desenvolvimento da autonomia e da capacidade de tomar decisões, de avaliar e resolver problemas para que assim o aluno aproxime as situações do cotidiano de conceitos e teorias do Ensino de Ciências.

Os discentes concordaram também que a utilização de vídeo aulas e a inserção de discussões ou debates como recurso didático tem ocorrido em ambas instituições (públicas e privadas). Quando indagados sobre a realização de excursões, tanto na escola pública como privada os estudantes discordaram em 
relação a sua realização. Muitos obstáculos cercam essa última modalidade didática, mas poderiam ser sanados segundo KRASILCHIK (2011) por meio de trabalhos de campo locais, sem a obrigatoriedade de autorizações ou necessidade de veículos para transporte. Vale ressaltar a importância de se utilizar mais de uma modalidade didática durante as aulas, com o intuito de manter os alunos sempre atentos. KRASILCHIK (2011, p 79) destaca que "a escolha da modalidade didática dependerá dos objetivos a serem alcançados, do conteúdo abordado, tempo e recursos disponíveis". Já de acordo com BETTENCOURT et al. (2014) o professor continua a desempenhar um papel fundamental na sala de aula, concebendo e implementando estratégias de ensino, de aprendizagem e de avaliação que promovam uma postura ativa por parte dos estudantes.

$\mathrm{Na}$ seção 3 do questionário investigativo os alunos foram indagados se haveria influência da Biologia para a escolha de sua futura profissão, e qual seria a profissão almejada (Figura 1).

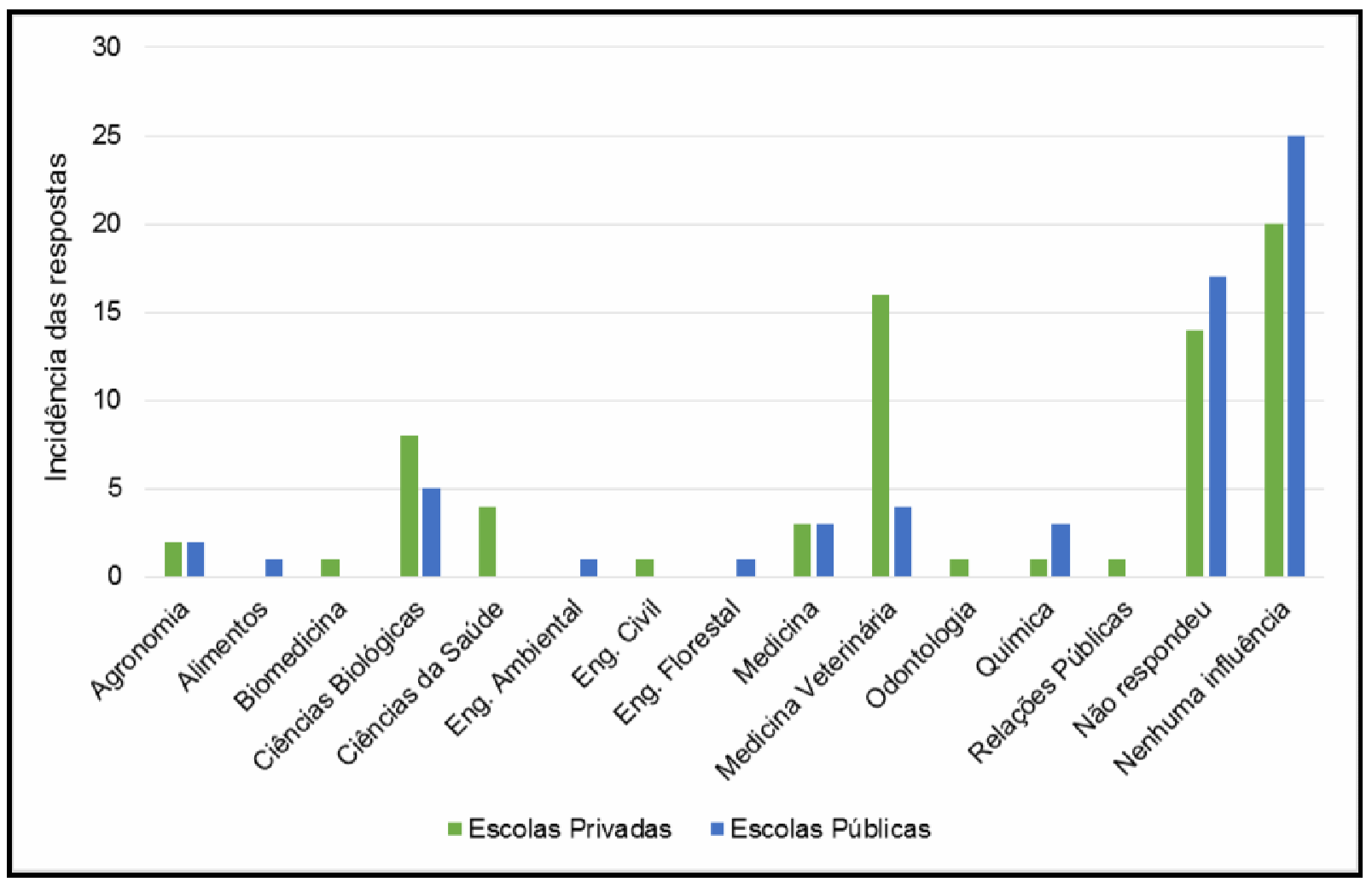

FIGURA 1. Cursos almejados pelos alunos respondentes e a incidência da influência da Biologia para a escolha de sua futura profissão.

Em resposta à "influência da Biologia para a escolha de sua futura profissão" foram encontradas diversas afirmações. A principal delas destaca as subáreas das Ciências Biológicas como estimuladoras na escolha do futuro curso superior e profissão. Tem-se que alunos que se identificaram com a zoologia almejam Medicina Veterinária para sua futura profissão; estudantes que se identificaram com botânica optaram pela Agronomia; já aqueles que se identificaram com anatomia e fisiologia humana optaram pela Medicina ou quaisquer outra profissão relacionada a área da saúde. Nas escolas privadas, o curso mais almejado, influenciado pela disciplina de 
Biologia é o curso de Medicina Veterinária. Enquanto isso, nas instituições públicas nota-se que as Ciências Biológicas se destaca dentre outros cursos.

\section{CONCLUSÃO}

Para os alunos respondentes de escolas públicas e privadas, a definição de Biologia é considerada de forma abrangente, possuindo caráter conceitual, científico, ecológico, zoológico e antropológico.

A falta de aulas práticas influenciou negativamente no ensino da disciplina. $E$ a relação desarmônica entre docentes e discentes é o principal ponto negativo em relação à disciplina de Biologia, fato que pode ter afetado o interesse dos discentes, visto que estes apenas concordaram sobre buscar informações do conteúdo aplicado em sala de aula.

A principal aplicação do estudo de Biologia para os alunos é a formação para o ENEM e vestibulares, podendo ser aplicada também para o melhor entendimento das relações do ser humano com o meio ambiente. Tal afirmação está diretamente ligada ao fato de que, para grande parte dos alunos, a disciplina não tem influência sobre a escolha da profissão almejada.

A indisciplina é um fator que tem interferido no andamento das aulas de Biologia, sendo que os alunos de instituições públicas concordam que a melhor forma de agir perante esta é planejar e realizar atividades práticas e interativas, já em instituições privadas os alunos concordam que associar os conteúdos a assuntos considerados interessantes é melhor.

Tais conclusões induzem a reflexões sobre a urgente necessidade de maior contextualização da Biologia enquanto componente curricular no Ensino Médio, aproximando os conceitos teóricos do cotidiano do aluno, o que poderia atribuir reais significados ao que se ensina em sala de aula.

\section{REFERÊNCIAS}

AQUINO, J. G. A indisciplina e a escola atual. Revista da Faculdade de Educação, v. 24, n. 2, p. 181-204, 1998.

BELOTTI, S. H. A.; FARIA, M. A. relação professor/aluno. Revista Eletrônica Saberes da Educação, v. 1, n. 1, p. 1-12, 2010.

BETTENCOURT, C.; ALBERGARIA-ALMEIDA, P.; VELHO, J. L. Implementação de estratégias ciências-tecnologia-sociedade (CTS): percepções de professores de Biologia. Investigações em Ensino de Ciências, v. 19, n. 2, p. 243-261, 2014.

BORGES, R. M. R.; LIMA, V. M. R. Tendências contemporâneas do ensino de Biologia no Brasil. Revista Electrónica de Enseñanza de lãs Ciencias, Espanha, v. 6, n. 1, p. 165-175, 2007.

BRASIL. Ministério da Educação. Secretaria de Educação Média e Tecnológica. PCN+ Ensino Médio: orientações educacionais complementares aos Parâmetros Curriculares Nacionais. Ciências da Natureza, Matemática e suas Tecnologias. Brasília: MEC/SEMTEC, 2002.

DELORS, J. A educação para o século XXI: questões e perspectivas. Porto Alegre: Artmed, 2005. $256 \mathrm{p}$. 
DEMO, P. Educação Hoje-" novas" Tecnologias, Pressões e Oportunidades. Revista Brasileira de Formação de Professores, v. 1, n. 1, 2009.

GARDNER, H. Estruturas da mente: a teoria das inteligências múltiplas. Porto Alegre: Artes Médicas, 1994.

GILES, T. História da Educação. São Paulo: E.P.U., 1987.

GIORDAN, A.; VECCHI, G. de. Origens do Saber: das concepções dos aprendentes aos conceitos científicos. 2. ed. Porto Alegre: Artes Médicas, 1996.

HOFFMANN, M. B.; SCHEID, N. M. J. Analogias como ferramenta didática no ensino de biologia. Ensaio Pesquisa em Educação em Ciências, v. 9, n. 1, p. 1-17, 2007.

KRASILCHIK, M. Prática de Ensino em Biologia. 4a. Ed. São Paulo: Editora da Universidade de São Paulo, 2011.

LIKERT, R. A technique for the measurement of attitudes. Archives of Psychology, v. 140, p. 1-55, 1932.

LIMA, L. P. D. Atitudes: Estrutura e mudança. Psicologia social, v. 7, p. 187-225, 2000.

MALAFAIA, G.; BÁRBARA, V. F.; RODRIGUES, A. S. D. L. Análise das concepções e opiniões de discentes sobre o ensino da biologia. Revista Eletrônica de Educação, v. 4, n. 2, p. 165-182, 2010.

MALAFAIA, G.; RODRIGUES, A. S. L Uma reflexão sobre o Ensino de Ciências no nível Fundamental da Educação. Ciência \& Ensino (ISSN 1980-8631), v. 2, n. 2, p. 1-9, 2008.

MATTAR, F. N. Pesquisa de marketing. Edição Compacta. São Paulo: Editora Atlas, 2001.

MORAN, J. M. A educação que desejamos: novos desafios e como chegar lá. Campinas: Papirus Editora, 2007.

PINHEIRO, N. A.; SILVEIRA, R. M. C. F.; BAZZO, W. A. O contexto científicotecnológico e social acerca de uma abordagem crítico-reflexiva: perspectiva e enfoque. Revista Iberoamericana de Educatión, n. 49, v. 1, p. 1-14, 2009.

SANMARTÍ, L. Educación sanitária: princípios, métodos e aplicaciones. Madrid: Diaz de Santos, 1988.

SCHELEY, T. R.; SILVA, C. R. P.; CAMPOS, L. M. L. A motivação para aprender Biologia: o que revelam alunos do Ensino Médio. SBEnBio, n. 7, p. 4965-4974, 2014. 
SCHWARTZMAN, S.; BROCK, C. Os desafios da educação no Brasil. Rio de Janeiro: Nova Fronteira, p. 9-51, 2005.

SOUTO, E. K. S. C.; SILVA, L. S.; SODRE, L.; SILVA, S. C. L. A utilização de aulas experimentais investigativas no ensino de Ciências para abordagem de conteúdos de microbiologia. Experiências em Ensino de Ciências, n. 2, v. 10, p. 59-69, 2015.

VIEIRA, L. D.; CASTRO, A. A.; CARVALHO, C. V. M.; SILVA, L. A. S. Uso de laboratórios de Biologia no IF Goiano - Câmpus Urutaí. Enciclopédia Biosfera, v. 11, n. 21, p. 2760-2768, 2015.

VYGOTSKI, L. S. Obras escogidas. Madrid: Visor, v.4, 1996, p. 64.

ANEXO I- Questionário aplicado aos alunos participantes da pesquisa.

\section{QUESTIONÁRIO INVESTIGATIVO}

Você está sendo convidado(a) a participar voluntariamente da nossa pesquisa. Nosso objetivo é conhecer e levantar alguns aspectos que permeiam a disciplina de Biologia entre os alunos da $3^{a}$ série do Ensino Médio das escolas públicas e privadas da cidade de Pires do Rio - GO. Destacamos que nosso intuito não é, em hipótese alguma, fazer juízo de valor dos participantes desta pesquisa e garantimos que todos os dados obtidos serão utilizados APENAS para fins acadêmicos. Qualquer informação complementar sobre o projeto de pesquisa, metodologia, dentre outros, pode ser obtida direto com o Coordenador do projeto. Em caso de aceite em participar da nossa pesquisa, responda, por favor, com atenção às questões que se seguem e ao Termo de Consentimento Livre e Esclarecido (TCLE).

1" SEÇÃO:

1. Idade:

2. Sexo: ( ) Masculino ( ) Feminino

3. Reside em área: ( ) urbana ( ) rural

4. Qual o grau de escolaridade de seu pai? mãe?
( ) Ensino Fundamental incompleto
( ) Ensino Fundamental completo
( ) Ensino Médio incompleto
( ) Ensino Médio completo
( ) Ensino Superior incompleto
( ) Ensino Superior completo
( ) Nenhum

Ensino Fundamental incompleto

( ) Ensino Fundamental completo

( ) Ensino Médio incompleto

( ) Ensino Médio completo

( ) Ensino Superior incompleto

( ) Ensino Superior completo

( ) Nenhum

6. Você já foi reprovado em Biologia? ( ) Sim ( ) Não

7. Você trabalha? ( ) Sim ( ) Não

Em caso afirmativo, em que tipo de atividade?

2 SEÇÃO: 
Para cada afirmativa abaixo, por favor, atribua um valor de 1 a 4 , considerando a escala ao lado:
1: Concordo plenamente

2: Concordo

3: Discordo

4: Discordo completamente

I. Para você, Biologia é:

1. O estudo dos seres vivos.

2. Estudos relacionados a novas descobertas relacionadas a cura de doenças, como desenvolvimento de medicamentos e vacinas.

3. O estudo da distribuição, abundância e relações dos seres vivos em diferentes ecossistemas.

4. Estudo dos animais e características relacionadas a suas estruturas e comportamento.

5. Estudo do ser humano, sua anatomia, fisiologia, comportamento e evolução.

II. Fatores que interferem negativamente no ensino de biologia.

1. A grande quantidade de termos técnicos.

2. Grande volume de informações em pouco espaço de tempo.

3. Indisciplina e desinteresse dos alunos.

4. Falta de qualificação adequada dos professores.

5. Falta de laboratórios e aulas práticas.

III. Uma boa aula de biologia possui:

1. Desenvolvimento de aulas práticas.

2. Participação em excursões, realização de feiras e mostras científicas.

3. Resolução de exercícios de fixação e/ou vestibulares.

4. Atividades em grupo, tais como seminários.

5. Utilização de recursos tecnológicos.

IV. São características negativas de um professor de biologia:

1. Que leia textos em sala de aula e priorize a memorização de conceitos.

2. Que peça a você que faça resumos de capítulos.

3. Que seja inseguro com relação ao domínio do conteúdo.

4. Que seja tolerante à indisciplina.

5. Que não tenha uma boa relação com a turma.

V. Aplicações do estudo de biologia no Ensino Médio.

1. Formação para o vestibular/ENEM.

2. Aquisição de informações úteis à vida cotidiana.

3. Compreensão sobre prevenção de doenças.

4. Possibilitar maior conservação dos recursos naturais.

5. Entender melhor as relações do ser humano com o ambiente.

VI. Quanto à sua relação com biologia:

1. De muito interesse pelos assuntos e é participativo durante as aulas.

2. Busca informações além do conteúdo de sala de aula.

3. Acha que os conhecimentos da disciplina facilitam a compreensão de fatos do cotidiano.

4. Conteúdos extremamente complexos.

5. Respeito pelos seres vivos e preocupação com a conservação.

VII. Com relação à indisciplina em sala de aula, o professor deve:

1. Punir o aluno expulsando-o da sala de aula ou advertindo-o verbalmente.

2. Conversar com o aluno, procurando entender os motivos que levam

ao desinteresse.

3. Planejar e realizar atividades práticas e interativas.

4. Associar os conteúdos de Biologia a assuntos considerados

interessantes.

5. Desprezar o aluno desinteressado.

VIII. Relacionado a metodologia utilizada pelo professor: 


\begin{tabular}{|c|c|}
\hline 1. Aulas práticas em sala e/ou laboratório. & ( \\
\hline 2. Aulas expositivo-dialogada utilizando livro didático, quadro e giz. & ( \\
\hline 3. Vídeo aulas. & ( \\
\hline 4. Excursões & ( \\
\hline 5.Debates ou discussões & ( \\
\hline
\end{tabular}

3 SEÇÃO:

A Biologia influencia na escolha da sua profissão? De que forma se dá essa influência e qual é sua profissão almejada? 